\title{
O Projeto Cirandar na formação docente: Registros formativos
}

\author{
The Cirandar Project in teacher education: Developmental records \\ El Proyecto Cirandar en la formación docente: Registros formativos
}

Recebido: 09/04/2021 | Revisado: 16/04/2021 | Aceito: 19/04/2021 | Publicado: 03/05/2021

Larissa Rodrigues de Oliveira
ORCID: https://orcid.org/0000-0002-2444-8956
Universidade Federal do Rio Grande, Brasil
E-mail: lara.adm11@ gmail.com
Danielle Müller de Andrade
ORCID: https://orcid.org/0000-0002-4952-7570
E-mail: danielleandrade@ @ifsul.edu.br
Elisabeth Brandão Schmidt
Instituto Federal de Educação Ciência e Tecnologia Sul-rio-grandens, Brasil
ORCID: https://orcid.org/0000-0002-7961-7593
Universidade Federal do Rio Grande, Brasil
E-mail: elisabethlattes@gmail.com
Fabiana Celente Montiel
ORCID: https://orcid.org/0000-0002-9921-6703
E-mail: fabianamontiel@ifsul.edu.br

\section{Resumo}

Este artigo, derivado de uma dissertação de mestrado, tem como objetivo apresentar a experiência formativa desenvolvida no Projeto Cirandar: rodas de investigação desde a escola e sua contribuição para a formação continuada de professores/as. Teve como pressuposto o entendimento de que a formação continuada demanda engajamento, diponibilidade, escuta atenta e partilha de conhecimento. Os dados, produzidos a partir dos diários escritos por um grupo de professores/as, participantes do Projeto Cirandar, desenvolvido no município do Rio Grande, Rio Grande do Sul, foram analisados por meio da metodologia de Análise Textual Discursiva proposta por Moraes e Galiazzi. Os resultados evidenciaram que a participação no Projeto Cirandar estimulou a escuta e o reconhecimento do/a outro/a, incitando o desenvolvimento de práticas pedagógicas coletivas que contribuem para a identificação com a profissão docente. $\mathrm{O}$ estudo fez emergir a importância da partilha da experiência docente, do acolhimento, da reflexão sobre os acontecimentos no âmbito escolar e do estímulo à autonomia dos/das professores/as para a (re)significação das práticas docentes.

Palavras-chave: Formação continuada; Projeto cirandar; Prática docente; Ensino.

\begin{abstract}
This paper, which is based on a Master's thesis, aims at introducing educational experiences developed by the Cirandar Project: investigation groups in school and their contribution to teachers' continuing Education. Its assumption was that continuing Education requires commitment, availability, listening skills and knowledge sharing. Data were collected in diaries written by a group of teachers who took part in the Cirandar Project developed in Rio Grande, Rio Grande do Sul, Brazil, and analyzed by the Discursive Textual Analysis, the methodology proposed by Moraes and Galiazzi. Results showed that participation in the Cirandar Project stimulated listening to and acknowledging others, besides triggering the development of collective pedagogical practices that contribute to teachers' identification with their occupations. The study highlighted the importance of sharing teaching practices, welcoming, reflection on school events and encouragement of teachers' autonomy to (re)signify teaching practices.
\end{abstract}

Keywords: Continuing education; Cirandar project; Teaching practices; Teaching.

\section{Resumen}

Este artículo, procedente de una tesis de maestría, tiene como objetivo presentar la experiencia formativa desarrollada en el Proyecto Cirandar: ruedas de investigación desde la escuela y su contribución a la formación continua del profesorado. Se basó en el entendimiento de que la educación continua requiere compromiso, disponibilidad, escucha atenta e intercambio de conocimientos. Los datos, producidos a partir de los diarios escritos por un grupo de docentes, participantes del Proyecto Cirandar, desarrollado en la ciudad de Rio Grande, Rio Grande do Sul, fueron analizados utilizando la metodología de Análisis Textual Discursivo propuesta por Moraes y Galiazzi. Los resultados mostraron que la participación en el Proyecto Cirandar estimuló la escucha y el reconocimiento del otro/a, fomentando el desarrollo de prácticas pedagógicas colectivas que contribuyan a la identificación con la profesión docente. El estudio destacó la importancia de compartir la experiencia educativa, acoger, reflexionar sobre los hechos del entorno escolar y fomentar la autonomía del profesorado para el (re)significado de las prácticas docentes. 
Palabras clave: Educación continua; Proyecto cirandar; Práctica docente; Ensenãnza.

\section{Introdução}

Docência é substantivo feminino originado do latim docens, particípio presente do verbo latino docere que se refere a “ensinar". Na língua portuguesa, o termo surgiu por volta de 1877, etimologicamente designando o "ato de ensinar", "qualidade do docente". Por possuir amplo conceito, haja vista que o ato de ensinar difere de acordo com a época, lugar e cultura, investigar a formação docente torna-se imprescindível à educação no sentido de contribuir para a qualificação dos processos formativos de educadores/as.

Para tanto, faz-se necessário considerar os diversos elementos presentes nas dinâmicas da formação docente, ou seja, ponderar sobre quem ensina, para quem ensina, em que contexto ensina, o que ensina, por quais motivos ensina, bem como em quais condições ambientais, objetivas e subjetivas ocorrem os processos de ensino e de aprendizagem. Importa também a compreensão de que a profissão docente é imbuída de saberes técnicos, científicos e, também de conhecimentos sensíveis, como sinalizado por Cunha (1989, pp. 169-170):

A formação do educador é um processo, acontecendo no interior das condições históricas em que ele mesmo vive. Faz parte de uma realidade concreta determinada, que não é estática e definitiva. É uma realidade que se faz no cotidiano. Por isso, é importante que esse cotidiano seja desvendado. O retorno permanente da reflexão sobre a sua caminhada como educando e como educador é que pode fazer avançar o seu fazer pedagógico.

Considerando a profundidade de cada experiência vivida, tanto na formação como no exercício da docência, emerge a necessidade do compartilhamento de reflexões bem como de formação coletiva permanente. Estudos tem confirmado a importância da formação continuada e o investimento na mesma para a qualificação da prática docente (Reis et al., 2019; Lidoino et al., 2020; Silva et al., 2021; Menezes et al., 2021; Santos et al., 2021). Os anseios e frustrações, as conquistas e alegrias, o receio e as aprendizagens precisam ser discutidos e registrados, pois fazem parte da experiência que (re)significa a docência.

Nesse sentido, torna-se necessário a criação e promoção de espaços formativos que contemplem as múltiplas formas de pensar e exercer a docência, como esclarecem Galiazzi et al. (2013, p. 158):

[...] a formação acadêmico-profissional em que professores registram, conversam, escrevem, reescrevem e problematizam suas práticas educativas em Rodas de Formação na Escola e assim partilham os sentidos atribuídos a suas práticas, promovem espaços de pesquisa, planejamento e de organização das ações educativas em um processo de construção de parcerias e de formação acadêmico-profissional. Nossa aposta formativa está na constituição de comunidades aprendentes sobre ser professor, com o objetivo de compreender e desenvolver práticas pedagógicas que promovam a aprendizagem dos participantes.

Entendendo que a formação docente resulta das inúmeras relações estabelecidas durante os processos formativos que ocorrem em distintos ambientes, ou seja, na universidade, na escola e na vida cotidiana de professores/as objetivamos, neste artigo, apresentar a experiência formativa desenvolvida no "Projeto Cirandar: rodas de investigação desde a escola" e sua contribuição para a formação permanente e continuada de professores/as.

\section{Projeto Cirandar: Rodas de Investigação desde a Escola}

O "Projeto Cirandar: rodas de investigação desde a escola" ${ }^{1}$ ancora-se em premissas freirianas como a de que a

\footnotetext{
${ }^{1}$ Desenvolvido pela Universidade do Rio Grande - FURG, em parceria com a $18^{\circ}$ Coordenadoria Regional de Educação (CRE), teve início no ano de 2012 na intenção de reestruturar o currículo do Ensino Médio do município do Rio Grande, Rio Grande do Sul, com o foco nas
} 
construção do saber se dá de forma coletiva, compartilhada e dialógica, tendo o diálogo como diretriz da experiência formativa. Leva em consideração os contextos escolares e as vidas dos/as professores/as, bem como suas resistências e lutas, além de seus entendimentos sobre a própria formação docente. Assim, configura-se como um espaço para repensar as práticas docentes, ao mesmo tempo em que confronta os conhecimentos acadêmicos às realidades escolares, dando margem para que os/as docentes entendam e conheçam suas próprias possibilidades e limitações. Conforme Schmidt e Galiazzi (2013, p. 16):

O pressuposto formativo é que os professores envolvidos no processo de formação produzam seus relatos de experiência e durante a sua produção desenvolvam a escrita, o diálogo, a leitura crítica entre pares, o trabalho coletivo e a partilha de saberes e vivências [...].

O Projeto prevê a formação acadêmico-profissional com vistas a integrar escola e universidade; rodas de conversa e investigação, para dialogar sobre as experiências de sala de aula; rodas de escrita - onde são desenvolvidos os relatos dessas experiências; rodas de leitura crítica - etapa em que existe a troca de relatos - e elaboração de parecer sobre a escrita do colega; reescrita e reenvio dos pareceres via sistema da Universidade Federal do Rio Grande - FURG; e, leitura dos relatos que serão apresentados no encontro final presencial do Projeto Cirandar. São realizados dois encontros presenciais: um durante o processo e outro no encerramento, onde os diários produzidos no decorrer do semestre são entregues à coordenação. As demais etapas são previstas para serem realizadas à distância. Importa salientar que esses encontros presenciais estão suspensos desde o ano de 2020, em decorrência da necessidade de distanciamento sanitário imposto pela pandemia da COVID-19².

As atividades do Projeto Cirandar configuram-se como uma tentativa de compreender a construção da docência para além da formação acadêmica, pois transpassam o ambiente universitário, perpassando as salas de aula públicas e privadas. O Projeto Cirandar considera mais do que práticas, metodologias e perspectivas pedagógicas ao propiciar "o exercício da escuta e o compartilhar dos saberes", produzindo "junto aos participantes do Projeto, uma atmosfera que remeta ao sentido de pertencimento a um país, à própria escola e à formação de professores [...]”. (Schmidt \& Galiazzi, 2013, pp.14-15).

Os pressupostos teóricos do Projeto implicam valorizar a aula de cada professor/a para pensar a formação; a escrita das experiências de sala de aula como foco coletivo e ferramenta cultural; a aprendizagem dialógica e coletiva; e a leitura entre pares, o que intensifica a formação e a (re)significação da docência. Ratificando, esse processo de formação proporciona diversidade de entendimentos e uma gama de maneiras de analisar, compreender e obter resultados positivos sobre o desenvolvimento profissional dos/as docentes. O processo formativo inclui aquilo que os/as toca e os/as modifica, visto que os relatos inscritos no Projeto Cirandar são a prova dessas experiências, a constatação de que a sala de aula está sendo vivida, sentida, experimentada e não constitui apenas um acontecimento que simplesmente "passa". (Larrosa, 2015).

É importante, portanto, que a formação continuada seja um contínuo na profissão da docência, uma vez que, a aprendizagem é um processo que acontece ao longo da vida, por isso, o professor é um profissional que precisa está em busca de novos conhecimentos, pois sempre tem algo a ensinar e aprender. (Menezes et al., 2021, p. 8).

Tais fatos corroboram a importância de articular escola e universidade, proposta formativa do Projeto, que visa compartilhar responsabilidades entre essas instituições, no que tange à formação inicial e continuada dos/as profissionais da educação. Importa enfatizar a relevância dos saberes teóricos nas realidades escolares e não apenas o exercício de repetição de técnicas, métodos e estratégias de pouco efeito transformador. Por esse viés, Pimenta (2010, p. 49) defende que “[...] o papel da teoria é oferecer aos professores perspectivas de análise para compreender os contextos históricos, sociais, culturais,

experiências de professores/as da disciplina de Seminários Integrados, promovidos pela rede municipal. Posteriormente, a proposta foi ampliada e atualmente é estendida à licenciandos/as e pesquisadores/as que tenham interesse em refletir sobre suas práticas de sala de aula.

2 A COVID-19 é uma doença causada pelo coronavírus denominado SARS-CoV-2 que, instaurada mundialmente no ano de 2019, tem ceifado a vida de milhares de pessoas. 
organizacionais, e de si mesmos como profissionais, nos quais se dá sua atividade docente, para neles intervir, transformandoos".

Essas perspectivas de análise são materializadas nas escritas desenvolvidas nos diários, trazendo a elas o tom de reflexão, distanciando do que Freire (2016) define como amesquinhar o caráter formador do exercício educativo. Nas palavras do autor: "É por isso que transformar a experiência educativa em puro treinamento técnico é amesquinhar o que há de fundamentalmente humano no exercício educativo: o seu caráter formador" (Freire, 2016, p. 34). Portanto, as experiências relatadas nos diários, escritos durante o Projeto Cirandar, são fonte de experiências que transpassam o simples "fazer educativo", valorizando a prática profissional como "momento de construção de conhecimento por meio de reflexão, análise e problematização" (Pimenta, 2010, p. 48).

Nesse sentido, a leitura entre pares motiva os/as participantes do Projeto a enxergarem a sua própria prática reconhecida no olhar do/a outro/a. Não o olhar de análise e julgamento, mas aquele que compartilha da aprendizagem e colabora com o crescimento da experiência do/a colega, visto que o processo de ler e reler os relatos dos pares convida ao exercício de reflexão sobre si mesmo, a partir da vivência do/a outro/a. Uma reflexão crítica que envolve o "movimento dialético entre o fazer e o pensar sobre o fazer" (Freire, 2016, p. 39), reiterando a premissa da ação profissional que forma e transforma.

Assim, com base nessas perspectivas, a proposta do Projeto Cirandar foi desenvolvida, primeiramente em 2012, para atender aos/às docentes que lecionavam no Ensino Médio, ministrando as disciplinas de Seminário Integrado ${ }^{3}$. Naquele primeiro ano, não foram elaborados diários, mas sim relatos, que são escritas mais sucintas sobre as experiências escolhidas para serem refletidas. Em edições posteriores, tais relatos configuram-se como parte do processo e objeto da etapa de leitura entre pares.

Nos dois primeiros anos - 2012 e 2013, a captação dos/as participantes foi realizada por meio de visitas aos núcleos que reuniam todas as escolas públicas de Ensino Médio do município de Rio Grande, iniciando a proposta da construção de diários. Nos anos posteriores, o processo foi ampliado para licenciandos/as e professores/as das redes (públicas e privadas), mantendo o foco no intuito de uma formação conjunta, coletiva, voluntária e direcionada ao pressuposto de formação por meio de comunidades aprendentes.

A ideia de comunidades aprendentes, segundo Galiazzi e Schmidt (2016), decorre do termo "comunidades de prática", empregado por Lave e Wenger e aprofundado por Wenger (1998), para nomear aquelas em que se aprende a viver em comunidade, com objetivo comum, exercendo atividades onde todos/as estejam engajados/as. No caso específico do Projeto Cirandar, as atividades compartilhadas são as leituras, escritas dos relatos, aprofundamento teórico, leitura crítica do relato do/a colega e a produção de diários reflexivos.

\section{Percurso Metodológico}

Os diários escritos durante o desenvolvimento do Projeto Cirandar foram objeto de pesquisa de natureza qualitativa (Oliveira, 2019), possibilitando desvendar as subjetividades expressas nas narrativas dos participantes da formação continuada. De acordo com o pensamento de Moraes e Galiazzi (2011, p. 11), o processo investigativo foi desenvolvido no entendimento de que a "pesquisa qualitativa pretende aprofundar a compreensão dos fenômenos que investiga a partir de uma análise rigorosa e criteriosa desse tipo de informação".

Caracterizou-se como um estudo documental que teve como corpus de análise os diários de trinta e sete professores/as

\footnotetext{
${ }^{3}$ Componente curricular do Ensino Médio Politécnico nas escolas estaduais de Ensino Médio do Rio Grande do Sul. Tem como objetivo desenvolver propostas de pesquisa de projetos em consonância com os eixos temáticos do componente curricular (Natureza, Humanas, linguagens e Matemática) e com atividades vinculadas ao mercado de trabalho, proporcionando o aprendizado em conjunto com a prática.
} 
participantes do Projeto Cirandar. A fim da identificação e preservação das suas identidades foi atribuído aos seus diários um código formado por três letras. Tais diários encontram-se disponíveis no site ${ }^{4}$ oficial do Projeto Cirandar.

Para a análise das informações recorremos à metodologia de Análise Textual Discursiva (ATD), proposta por Moraes e Galiazzi (2011). A ATD é uma metodologia de análise que transita entre a análise de conteúdo e a análise do discurso, onde se busca a compreensão e a reconstrução de um fenômeno ou discursos, tendo na escrita o movimento de organizar e sistematizar o pensamento, construir conhecimento e compreender o fenômeno investigado. As etapas da ATD contemplam a unitarização do corpus de análise, ou seja, sua fragmentação e codificação, onde cada unidade foi identificada com o código de letras atribuído ao diário correspondente aos códigos estabelecidos para cada diário, acrescido de três números referentes ao ano da escrita e a sua localização no corpo do texto. A partir da unitarização foram construídas as categorias iniciais, intermediárias e finais, sucessivamente. As categorias finais encaminharam para a escrita de metatextos, dentre eles o denominado "Docência: uma história escrita a muitas mãos", o qual será apresentado no tópico a seguir.

\section{Docência: uma História Escrita a Muitas Mãos}

A proposta formativa desenvolvida pelo Projeto Cirandar possibilita aos/às participantes reviver suas práticas docentes por meio do diálogo entre pares e da escrita de diários. O compartilhamento dos registros entre os/as participantes, bem como a partilha oral de experiências pedagógicas vivenciadas instigam novas compreensões e (re)significações a respeito da docência. Autores/as destacam a importância da constante reflexão crítica do fazer pedagógico, muitas vezes proporcionada através das formações continuadas (Lidoino et al., 2020; Silva et al. 2021; Menezes et al., 2021; Santos et al., 2021).

A experiência docente, cerne do processo formativo do Projeto Cirandar, é um termo oriundo da palavra experiência e relaciona-se à ação de experimentar, vivenciar, colocar em prática. Filosoficamente, o termo experiência pode ser entendido como todo conhecimento que se adquire diretamente da observação do mundo sem inferências; refere-se aos dados dos sentidos ou sensações em que o conhecimento se baseia. É ainda utilizado no sentido de experimentação científica por meio de manipulação de fenômenos e simulações laboratoriais.

Dewey (1971, p. 31) afirma que "[a] experiência não se processa apenas dentro da pessoa", ela é também resultado daquilo que foi transmitido anteriormente ao seu acontecimento. Segundo o autor, "as condições do meio modelam a experiência" (p. 32) e utilizar "as condições físicas e sociais do ambiente para delas extrair tudo que possa contribuir para um corpo de experiências saudáveis e válidas" (p. 32) torna-se um diferencial para que os acontecimentos vividos resultem em novas atitudes, pensamentos e ações. $\mathrm{O}$ autor acrescenta que os conceitos de interação e situação "são inseparáveis um do outro" (p. 36), portanto preponderantes na interpretação das experiências, visto que influenciam no significado que a elas é atribuído.

Com base nessa interação, uma das participantes do Projeto Cirandar enfatizou o quanto o compartilhamento das experiências proporcionou crescimento a ela como professora, aos/às licenciandos/as e à equipe escolar por intermédio das vivências no Programa Institucional de Iniciação à Docência (PIBID) ao escrever:

"Mais uma vez destaco que fazer parte do Pibid me proporciona muitos aprendizados. [...] estar ao lado dos licenciandos me trouxe recordações do tempo em que iniciava o meu processo de formação docente. Lembro-me bem das primeiras escritas, dos eventos, da insegurança em cada apresentação de trabalho e o quanto é importante nestes momentos de desafios estarmos ao lado dos colegas e dos professores que torcem por nós" (PDB201406).

"Importante destacar ainda nesta escrita que nos sentimos muito acolhidos em todas as escolas que realizamos nossos encontros. Em todas as visitas recebemos o carinho das professoras e funcionários das escolas, os quais manifestaram o quanto tem sido significativo a presença do Pibid na escola" (PDB201408).

\footnotetext{
${ }^{4}$ https://cirandar.furg.br/
} 
Nessa perspectiva, Freire (2011. p. 105) esclarece que a busca pelo ser mais "não pode realizar-se no isolamento, no individualismo, mas na comunhão, na solidariedade dos existires, daí que seja impossível dar-se nas relações antagônicas entre opressores e oprimidos". Assim encontramos nas narrativas pesquisadas a relevância das situações de socialização e compartilhamento das práticas docentes, respaldando as explanações acima. Entendemos que elas contribuíram para uma reflexão que possibilitasse (re)significar a docência a partir de experiências coletivas. "No tocante à realização dos processos formativos, vale ressaltar a sua importância enquanto espaço de troca, construção de diferentes aprendizados e solução de problemas, nos quais os participantes buscam partilhar suas experiências práticas.” (Santos et al., 2021, p. 14).

As experiências registradas tornam visível a significação dada pelos/as professores/as às experiências vividas coletivamente, à relevância do aprender em conjunto com o/a outro/a e ao que essas situações reverberaram em sua (re)significação sobre o ser docente, como mostram os registros a seguir:

"Mas por outro lado eles percebem que esta oportunidade de se fazer este estudo dentro da escola nos favorece bastante no sentido de nos aprofundar e ter um conhecimento ampliado através dessa proposta de Formação. Sendo que eles também estão gostando de poder se encontrar com seus colegas da área para planejar e dialogar no coletivo, isto eles não querem perder pois são unanimes em dizer que este espaço foi a melhor conquista que se teve ao longo dos anos, com tantas mudanças" (PVC201416)

"[...] concordo com a professora quando ela fala de que a escola e os professores têm que estar sempre trabalhando em conjunto com os professores da Universidade em sua formação continuada, sempre pensei assim, mas não tive essa oportunidade antes, me sentia isolada como se fosse uma ilha trabalhando sozinha na escola na minha disciplina, eu achava isso um terror, mas a oportunidade chegou agora com o Pacto e o Cirandar que abriram horizontes para mim, me sinto muito mais segura agora que tenho esse respaldo da Universidade" ( PVC201522)

A respeito da compreensão acerca do processo de reflexão com base nas experiências compartilhadas, as ideias de Trevisan (2014, p. 65) reafirmam que "[o] pensamento dispõe de uma instância ou experiência "externa" - do Outro - para repensar, desse modo, o que está instituído na racionalidade - no Mesmo - já formatado nos procedimentos habituais". Reitera que a (re)significação do que se entende sobre a docência e o ser docente pode ser constantemente modificada quando permitimos que o contato com o/a outro/a (colegas, discentes, ambiente) seja e se torne transformador. Os registros, a seguir possibilitam visualizar a reflexão sobre como as aprendizagens coletivas fomentam a (re)significação da docência:

"Entender o outro, como pensa, ter um olhar mais atento, projetar, tudo isso contribuiu para o meu crescimento. Entender o outro (e a mim mesma) como parte cheia e vazia ao mesmo tempo, cheia das vivências que trazemos cotidianamente, vazia porque precisamos aprender constantemente. Assim, me percebo nas funções que exerço, seja na família, no trabalho ou nas interações que estabelecemos com o outro" (PJL201501).

"Além disso acredito que toda a pessoa é as diversas marcas de outras tantas pessoas e, sendo assim, tudo que é dito pelos meus colegas e professoras corrobora, de certa maneira, com a minha construção enquanto pós-graduando, docente e pessoa" (PPK201511).

Tais anotações reiteram a defesa de Dewey, 1971; Freire, 2011; e Trevisan, 2014, quando enfatizam que o ambiente e as relações com o/a outro/a oferecem subsídios para ampliar conhecimentos, formar laços que contribuam para o crescimento profissional e pessoal, e consequentemente, buscar a compreensão sobre a docência. Confirmam também o que Brandão (2007, p. 7) menciona sobre a construção do conhecimento ao sublinhar que esta construção "[...] é começo da possibilidade de os seres vivos aprenderem não apenas diretamente do e com o seu meio natural, naturalmente, mas uns com os outros e uns entre os outros, culturalmente". O pensamento de Brandão (2007) coaduna ao de Freire (1981) para quem o conhecimento, resultado de processos de aprendizagem, decorre da aderência ao/a outro/a e da impregnação de sentidos, de percepções e significados, a fim de resultar em transformações perceptíveis.

Sobre aprendizagem coletiva os diários mostraram a (re)significação da prática a partir do conjunto, demonstrando que o processo de reavaliar a própria prática com base nas experiências compartilhadas é resultado da compreensão de que é 
possível aprender com a vivência do/a outro/a, de que não é preciso "errar o mesmo erro" para que a aprendizagem seja estabelecida. Esse fato é evidenciado por Lidoino et al. (2020, p. 10) ao destacarem que o "processo de ensinar e prender é uma engrenagem, que por si só apresentam resultados fragmentados e em conjunto, através de uma aprendizagem colaborativa a ação-reflexão e ação acontecem simultaneamente no ato de ensinar e aprender". Ao compartilhar as experiências, existe a possibilidade de replicar os acertos e evitar novos desvios, como mostra o excerto abaixo:

"O diálogo com os colegas, com as professoras e as discussões das leituras realizadas, me convidou a pensar em uma sala de aula diferenciada em que o planejamento é construído coletivamente com flexibilidade e que todos os envolvidos são protagonistas da sua formação" (PDB201511).

Entre os fatores atribuídos para que o processo de reflexão sobre a docência fosse fomentado estão a colaboração e o compartilhamento com os/as discentes, indo ao encontro do preconizado por Tardif (2004, p. 49) ao sinalizar que:

[o] docente raramente atua sozinho. Ele se encontra em interação com outras pessoas, a começar pelos alunos. A atividade docente não é exercida sobre um objeto, sobre um fenômeno a ser conhecido, ou uma obra prima a ser conhecida. Ela é realizada concretamente numa rede de interações com outras pessoas, num contexto onde o elemento humano é determinante e dominante [...].

Interação que tem como premissa a escuta atenta, conforme enfatizou Freire (2016, p. 114) ao indicar que "[é] preciso que quem tem o que dizer saiba, sem dúvida nenhuma, que, sem escutar o que quem escuta tem igualmente a dizer, termina por esgotar a sua capacidade de dizer por muito ter tido sem nada ou quase nada ter escutado". Para Freire (2016), a escuta é um processo complexo que se edifica gradativamente na busca da construção de um conhecimento crítico-emancipador.

Na perspectiva freiriana a escuta é pressuposto para que o/a docente fale com o/a educando/a e não apenas para o/a educando/a, a fim de tornar os processos de ensino e de aprendizagem experiências significativas para ambos/as. Escuta que deve estar presente também nas relações entre docentes, gestores/as escolares e comunidade escolar e que foram registradas nos diários, revelando a importância de escutar e ser escutado/a, bem como de escutar a si próprio, em especial quando se (re)vive a experiência no processo de escrita da mesma.

"Busquei me aproximar cada vez mais dos estudantes, conhecê-los a fim de buscar oficinas que se atrelassem aos interesses deles. Além disso, tentei estabelecer uma relação próxima com os profissionais convidados a desenvolver as oficinas, pois os mesmos não possuíam contato prévio com os educandos" (PPK201702).

"Importante ressaltar a necessidade de que se estabeleçam relações de parceria e afetividade entre docente e estudantes, a fim de que exista o respeito e a possibilidade de crescimento das intervenções e orientações" (PLN201509). "O primeiro e constante desafio é mantermos o diálogo entre as diferentes áreas do conhecimento e a partir das nossas vivências constituirmos juntamente com os licenciandos e com os professores da educação básica o subprojeto interdisciplinar" (PDB201402).

Com base nas narrativas enunciadas, observamos que o ato de escutar, bem como o reconhecimento do/a outro/a foram aspectos emergentes no processo de (re)significação docente, instaurado no Projeto Cirandar. Trevisan (2014) aponta que o reconhecimento do/a outro/a, como categoria-chave, é basilar no entendimento dos processos pedagógicos. Honneth (2003) complementa a assertiva, esclarecendo que esse reconhecimento do/a outro/a surge da aceitação de capacidades e qualidades dos/as outros/as e de si mesmo/a, que são aferidas nas relações dos/as homens e mulheres com outros homens e outras mulheres, com o mundo e consigo, ou seja, é na interação com o/a outro/a que aprendemos a reconhecê-lo/la e aceitálo/la, portanto a crescer com ele/ela, como mostra o registro a seguir:

"Agradeço [...] e ao Cirandar, pois a motivação de trabalhar Projetos veio desses encontros anuais, das leituras reflexivas, das experiências de outros professores que participam da roda. [...] por esses momentos de acolhimento ao professor que tanto necessita do apoio emocional de seus parceiros de trabalho para dar continuidade ao 
processo de ensino/aprendizagem, que começa na sala de aula, mas que se prolonga para a comunidade, para a sociedade [...]" (PCP201506).

A narrativa acima inaugura uma característica pontual sobre a concepção de docência, encontrada nas escritas e que pode ser entendida como fator motivador da profissão docente. Ficou evidenciado o resultado social dos processos educacionais, a permanência atemporal dos ensinamentos e das aprendizagens realizados e compartilhados entre os sujeitos envolvidos, em outras palavras, aquilo que fica socialmente instituído a partir do processo educacional.

$\mathrm{Na}$ intenção de corroborar a ideia de que a educação precisa ser fundamentada pela realidade que acolhe, Larrosa (2015, p. 63) pontua que “[...] a educação, segundo dizem, deve partir da realidade, o campo pedagógico é um gigantesco dispositivo de produção de realidade, de certa realidade”. Ao refletir criticamente sobre elas, os/as educadores/as tendem a ampliar a consciência sobre a estrutura social de sua prática e, ao mesmo tempo, questioná-la aprofundando o que eles/as entendem a respeito das diversas maneiras de desenvolver a educação e as consequências sociais dessa atividade (Contreras, 2002).

Esse movimento de pensar o fenômeno educativo instiga a consciência docente que, para Contreras (2002), é a autonomia sobre o fazer docente e o ser professor/a, que oferece sentido ao processo de ensino e educação social, mesclando teoria e prática no contexto em que são desenvolvidos processos educativos. $\mathrm{O}$ autor suscita o questionamento a respeito da distância entre o pensar e o executar a educação, ou seja, defende que o/a docente é quem tem o conhecimento para pensar e não apenas executar os processos educativos, retornando assim à busca pelo conceito de autonomia que foi ressaltado pelos/as participantes do Projeto Cirandar em suas escritas.

Importa salientar que as narrativas contidas nos diários de campo investigados exemplificam e embasam o conceito de professor reflexivo esclarecido por Alarcão (2003), especialmente, por ser um processo permanente e contínuo que se prolonga e amplia. De acordo com a autora:

[...] a noção de professor reflexivo baseia-se na consciência da capacidade de pensamento e reflexão que caracteriza o ser humano criativo e não como mero reprodutor de idéias e práticas que lhe são exteriores. É central, nesta conceptualização, a noção do profissional como uma pessoa que, nas situações profissionais, tantas vezes incertas e imprevistas, actua de forma inteligente e flexível, situada a reactiva. (Alarcão, 2003, p. 41)

A esse processo crítico reflexivo sobre a prática, um dos diários faz referência a sua trajetória ao descrever a relevância que o/a professor/a atribui ao apoio dos/as colegas e às práticas coletivas para a transformação das ações cotidianas, assim como demonstra o processo de maturidade docente proporcionado por uma maior compreensão acerca da própria docência e do cotidiano da profissão.

"Com relação ao trabalho em coletivo, este também teve início junto com o início da minha carreira docente, naquele momento foi a insegurança de uma professora inexperiente que me fez buscar apoio no diálogo com uma professora mais experiente, que por sua vez, me apresentou para o grupo [...] um coletivo de professores que se reunia na FURG para pensar a educação, que me fez compreender a importância do suporte mútuo entre nossos pares. Desde então tenho buscado parcerias entre colegas para o desenvolvimento de atividades de ensino e também procurei me manter ativa em coletivos de professores [...]" (PPZ201604).

“Esse processo coletivo de desenvolvimento da proposta ainda está em curso, e percebo nestes diálogos como é importante o apoio mútuo e a presença dos diversos olhares, por mais que tenhamos objetivos em comum, trazemos nossas experiências pessoais para a construção da proposta, e assim estamos enriquecendo nossas aprendizagens" (PPZ201602).

A partir das narrativas escritas pelos/as docentes, percebemos os três sentidos de um processo reflexivo atribuídos por Schön (2000), são eles: a reflexão-na-ação, a reflexão-sobre-a-ação e a reflexão-sobre-a-reflexão-na-ação. De acordo com o 
pedagogo, o pensar acerca das experiências enquanto elas acontecem, observando-as sem interrompê-las, é denominado de reflexão-na-ação. A reflexão-sobre-a-ação é a tentativa de reconstruir a ação já vivida modificando o que for possível de modo a antever situações semelhantes. Por sua vez, a reflexão-sobre-a-reflexão-na-ação é o processo de entendimento que leva à transformação das ações futuras, produz conclusões sobre as experiências e sobre os conhecimentos desenvolvidos a partir delas.

O processo de reflexão é algo que está presente na rotina do professor que, ao planejar, leva em consideração os momentos vivenciados em aula, com seus alunos, para, a partir desse processo reflexivo sobre o que aconteceu, o que foi positivo, o que poderia ser diferente, iniciar um novo planejamento. (Santos et al., 2021, p. 14).

Tais sentidos apontam para a necessidade dos/das docentes pensarem e repensarem as suas práticas pedagógicas de maneira crítica, como foi propiciado pelo Projeto Cirandar. O registro, via narrativas, ao mesmo tempo que possibilita (re)viver as experiências, faz emergir questionamentos. Esses, por sua vez, resultam em esclarecimentos e incitam novas ações, pautadas pelo movimento de pensar, repensar e transformar as experiências docentes, como mostrou-se nos seguintes registros:

"A participação como integrante do grupo de pesquisa [...] significa uma oportunidade de aproximação entre os docentes da escola básica e os do ensino superior, traçando metas em comum, convergindo em diálogos e sugestões, construindo caminhos para superação das dificuldades no que se refere à qualidade do ensino, através do compartilhamento das experiências, da reflexão de sua prática apoiada nas teorias dos autores que debatemos durante os encontros" (PLN201505).

"Outras vivências também foram narradas pelos colegas da turma, apontando a necessidade do diálogo e da escuta do professor, pois muitas são as experiências que devem ser socializadas e inquietações a ser problematizada em espaços coletivos de formação docente" (PDB201505).

Angers (2008) relativiza os processos de socialização que constituem as identidades profissionais, enfatizando os diversos instantes marcantes e os processos de remodelação dessas identidades, os quais são e estão imbricados às experiências de vida profissional. Para o autor, a construção das identidades surge de processos dinâmicos que nunca terminam e que estão sujeitos a diversas influências "por que nos mantemos sempre em contato com os outros, influenciando-os como eles nos influenciam a nós". (Angers, 2008, p. 61).

Ademais, o autor considera que as identidades são múltiplas, em virtude dos inúmeros grupos a que estamos ligados, e, também, pelo fato de que vivemos no dilema de sermos quem somos e, ao mesmo tempo, de sermos aceitos em determinados grupos sociais. Assumimos, segundo Angers (2008), diferentes comportamentos dependendo do tempo e lugar em que estamos inseridos/as e dos demais estímulos que nos circundam. A essa premissa o autor acrescenta que, como seres sociais que se relacionam, somos parte de uma rede e cada um de nós é um fio que mantém essa rede a qual, por sua vez, está sempre se modificando a medida que nos transformamos, pois "uma colectividade não se reduz a uma simples soma de indivíduos. Tudo decorre das relações que eles estabelecem, a dois, a vários ou com a sociedade no seu todo". (Angers, 2008, p. 62).

A experiência vivida durante a participação na disciplina de Seminário Integrado e no Projeto Cirandar, bem como dos processos de socialização delas, contribuiu para a descoberta de uma nova identidade docente, conforme revelam os registros a seguir:

"[...] não posso deixar de destacar o quanto esse espaço vem nos possibilitando a construção de uma identidade enquanto grupo de professores de S.I. e de pesquisadores que investigam sua sala de aula" (PCM201506).

"[...] destaco também o favorecimento de momentos de socialização. Mas para chegar a perceber a importância destes, primeiramente aprofundei minha compreensão sobre a experimentação em sala de aula" (PPZ201512).

Os relatos explicitam os processos de construção de conhecimento de maneira coletiva os quais fortalecem, nos/as 
docentes, o sentido de pertencimento a um grupo, de relevância de suas experiências. A partir delas, novos conhecimentos são estabelecidos, consolidando a ideia de que a formação profissional não se faz apenas individualmente, é preciso haver cooperação - fonte da tecitura dessa rede que é a coletividade. O sentido de coletividade, bem como a falta dele e as dificuldades de exercer mudanças estruturais de maneira pontual, quando não existe o comprometimento com o coletivo, trazem implicações ao desenvolvimento da profissão, como sinalizado abaixo: "A minha maior angústia sempre foi a solidão dentro da escola, pois sempre trabalhei em escolas pequenas então eu
era sozinha, atendia todas as turmas do turno em que eu trabalhava, não tinha com quem trocar ideias sobre o que
acontecia dentro da sala de aula, como eram desenvolvidas as aulas, isto foi me levando a uma acomodação, eu não
tinha um incentivo para mudar a maneira de dar aulas, embora eu nunca tenha seguido um ritual a cada ano eu fazia
tudo diferente não conseguia ficar na mesmice, gostava do que fazia embora não tivesse muita criatividade"
(PVC201503).

"[...] seria necessário que houvesse uma integração e dinâmica definida entre professor coordenador e professores auxiliares, de modo que todos trabalhassem juntos em busca dos mesmos objetivos. Contudo não se observou isso durante o $1^{\circ}$ trimestre, visto que os professores não conseguiam se encontrar para conversar sobre o andamento das aulas, a fim de unificar um trabalho coletivo. Esse descompasso entre os professores prejudicou o trabalho dos alunos [...] Reuniões que propiciem o encontro dos professores para planejarem a disciplina de SI (Seminário Integrado - grifo da autora) precisam ser marcadas pela coordenação escolar, preferencialmente em outro turno. $O$ que aconteceu foi que algumas reuniões foram marcadas em turnos opostos ao trabalho docente, mas muitos deles não compareceram, inviabilizando a organização de uma dinâmica mais uniforme de orientação" (PLN201506).

Os registros acima demonstram que a atividade docente é resultado de múltiplos esforços e de trabalho coletivo. Esta, demanda planejamento, organização, comprometimento e participação de todos/as envolvidos/as para que os resultados sejam satisfatórios. A esse respeito Vasconcellos (2015, p. 92) pontua que "[a] participação é um valor, é uma necessidade humana; é uma questão de respeito pelo outro, de reconhecimento de sua condição de cidadão, de sujeito de sentir, pensar, fazer, poder", a sua negação gera descomprometimento e relações conflituosas "com o mundo e, especialmente, com os outros homens na sociedade".

Durante a leitura das narrativas, pudemos compreender melhor o pensamento dos/as professores/as a partir da teoria da ação dialógica de Freire (2011), na qual os conceitos de colaboração e união se fazem presentes e estão associados à organização e à síntese cultural. Para o autor, na ação dialógica os "sujeitos se encontram para a transformação do mundo em co-laboração" (Freire, 2011, p. 227), sem dominação e baseados na comunicação horizontal, voltando-se para as realidades que os desafiam de forma a problematizá-las na busca pela libertação dos homens e mulheres, conforme expresso abaixo:

"[...] defendemos que há um processo de predisposição e interesse de cada indivíduo em colaborar com o outro, ao questionar, investigar, falar, escrever, ler, escutar, construir significados, como forma de buscar compreender os diferentes temas em estudo [...]" (PCM201711).

"[...] os caminhos estão sendo trilhados nas Rodas de Formação, em que a perspectiva da pesquisa individual passa a ser compartilhada no coletivo em um movimento dialético e dialógico para a formação coletiva e auto formação de cada sujeito" (PAM201518).

As narrativas mencionadas amparam-se no sinalizado por Vasconcellos $(2015$, p. 65) ao destacar que "o homem vai se constituindo enquanto tal por sua ação de transformação do mundo; movido por um espectro desejo, por uma incipiente curiosidade [...] a ação de intervenção do homem, no entanto, não era qualquer, já que tinha um direcionamento". As intencionalidades das ações dos homens e das mulheres participantes do Projeto Cirandar relacionam-se à ajuda mútua e ao trabalho coletivo decorrente da união e da participação.

Os movimentos de transformação das realidades, a partir de pequenas ações coletivas necessárias, foram sinalizados como desafios à equipe de coordenação e organização da disciplina de Seminário Integrado. 
"Foi criada pela escola uma hora por semana de reunião com os demais professores que atuam no Seminário Integrado, dos $2^{\circ}$ anos, onde eu conto com a colaboração desses colegas e mais a coordenação pedagógica que está sempre disposta a aprender junto com a gente e nos orientar neste sentido, de levar o melhor para os alunos. A pretensão é que todos os colegas interajam com o Seminário Integrado que até o momento não está acontecendo" (PVC201305).

"Estabelecer uma parceira com as famílias contribui de maneira significativa no desenvolvimento das crianças. Sendo assim, propus que os familiares dos educandos, participassem de uma atividade na escola. Para minha alegria quase todos compareceram e gostaram muito da proposta daquela manhã [...]" (PJL201605).

A reflexão, acerca do papel do/a professor/a na tarefa de aproximar a escola e a comunidade escolar, demonstra o quanto essa ação reverbera, positivamente, na prática docente. Ao sentir-se motivado/a, especialmente, o/a educador/a tende a perseverar e, por consequência, a incentivar os/as demais colegas e o corpo diretivo, conforme registros abaixo:

“Assim apostei no trabalho coletivo com os professores regentes e com os colegas da [...] Penso que a parceria com esses professores contribuiu significativamente para o desenvolvimento dos estágios colaborando com leituras, sugestões, indicações de materiais e informações relevantes sobre a turma” (PDB201522).

"A parceria com os professores regentes da escola contribuiu para que os estagiários se sentissem acolhidos na escola e sobretudo nas turmas, com mais segurança para o desenvolvimento das aulas” (PDB201523).

O aprimoramento da prática docente, da estruturação da formação inicial de licenciandos/as, a aproximação e participação de docentes da rede básica de ensino e o aprimoramento das atividades escolares foram o mote para estabelecer outras parcerias. Os registros acima possibilitam a compreensão acerca de como os processos de trabalho participativo e coletivo possuem abrangência para além do ambiente onde ele é pensado e executado.

Pimenta (2010, p. 140) sinaliza a necessidade de investigação das atividades pedagógicas, a fim de transformar o “saber fazer docente numa contínua construção e reconstrução de suas identidades a partir da significação social da profissão, bem como pelo significado que cada professor confere à docência em seu cotidiano e nas relações com seus pares [...]".

Em diversos momentos, as narrativas dos/as docentes trouxeram subsídios para a compreensão da (re)significação da docência feita a partir de transformações das práticas educacionais enraizadas. Tais transformações são atribuídas ao pensar coletivo, à ação- reflexão e baseadas nas práticas e experiências que levam em consideração os cenários, as possibilidades, as reais condições de movimentos para então elencar maneiras e estratégias para modificá-los.

"O cenário vem se modificando acompanhando as transformações da sociedade contemporânea. Assim a formação docente também merece atenção para enfrentar esses desafios perante a essas transformações” (PEP201702).

"[...] antes de podermos planejar e executar o projeto, é preciso estudar respeitando a individualidade de cada um, fazer uma proposta coletiva de forma integrada na construção do projeto [...]" (PEP201707).

Indubitavelmente, a atribuição da (re)significação docente, para os/as participantes do Projeto Cirandar, envolveu a noção do trabalho coletivo e a superação de algumas das caraterísticas da educação tradicional, como a centralidade de conhecimentos, a hierarquização de papéis, os discursos pragmáticos sobre a transferência de saberes e rejeição a mudanças.

Os registros realizados nos diários permitem-nos visualizar a emergência do fazer pedagógico diferente e da reflexão coletiva para que as transformações necessárias ocorram e permitam superar as dificuldades e atender as demandas da atualidade.

\section{Considerações Finais}

No caminho trilhado para compreender a (re)significação da profissão, manifestada a partir da reflexão das práticas docentes, percebemos o quanto a atitude crítica esteve presente nos diários dos/as professores/as e neles se revelaram, 
demonstrando que o registro de pensamentos e sentimentos podem se constituir para a efetivação de experiências educativas. Larrosa (2015) esclarece que, pensar a educação pelo viés da experiência, tem mais semelhança com a arte do que com técnica ou prática científica. Assim, é preciso atestar a relevância do processo de escrita acerca das experiências para a descoberta de alternativas que transformam o modo como a docência se configura: um fazimento e refazimento contínuo à semelhança da habilidade do artífice.

Diversas experiências relatadas nos diários contrariam o "senso comum" do meio educacional. Tais experiências estão imbuídas do pensamento crítico imerso em "como", "por que" e "de que forma" os processos educativos chegaram a ser como são e o que cada professor/a faz em sua atividade docente, possibilitando que o exercício da docência não seja, nem esteja, restrito a tarefas a serem cumpridas de modo automatizado e não reflexivo.

A importância da escrita reflexiva e da promoção de espaços de formação coletiva, semelhantes aos desenvolvidos pelo Projeto Cirandar, cuja base para novas propostas teóricas sobre o processo educacional advenham da prática escolar, foi fator preponderante nos registros dos/as docentes. Possibilitaram que houvesse transformações em suas concepções sobre a docência, que ocorrem em pequenos passos e que, com o tempo, se tornam movimentos maiores, os quais contribuem para a construção de uma nova realidade.

A realização desses espaços formativos coletivos, como ocorre no Projeto Cirandar, demonstra que a troca de experiências é uma oportunidade de acolhimento entre pares e propicia a reflexão acerca do cotidiano docente. Oportuniza momentos em que o/a docente se identifica com o coletivo de que faz parte, partilhando suas dúvidas e anseios e descobrindo, na fala do/a outro/a, as respostas que contribuem para o fortalecimento de seu modo de ser e estar professor/a.

Ademais, a experiência formativa proporcionada pelo Projeto Cirandar ao promover a integração entre instituições formadoras, como a universidade e a escola, engendra movimentos reflexivos cíclicos que contribuem para a qualificação das práticas pedagógicas de professores/as, bem como potencializa a reflexão crítica, o desenvolvimento da autonomia docente e a realização de um trabalho socialmente contextualizado, ampliando as possibilidades de (re)significação da docência e da educação.

Por fim compreendemos que processos formativos participativos e colaborativos contribuem para a formação de professores/as bem como para a qualificação das práticas pedagógicas e da Educação como um todo. Propostas formativas como a desenvolvida pelo Projeto Cirandar suscitam novas investigações no intuito de apontar caminhos e estratégias para a formação continuada de educadores/as, as quais colaborem para a reflexão acerca do fazer pedagógico.

\section{Referências}

Alarcão, I. (2003). Professores reflexivos em uma escola reflexiva. (2a ed.). Cortez.

Angers, M. (2008). A sociologia e o conhecimento de si: uma outra maneira de nos conhecermos graças à sociologia. (M. Carvalho, Trad.). Lisboa: Instituto Piaget.

Brandão, C. R. (2007). O que é educação Popular. Brasiliense.

Contreras, J. (2002). Autonomia de professores. (S. T. Valenzuela, Trad.). Cortez.

Cunha, M. I. da. (1989). O bom professor e sua prática. (20a ed.). Papirus.

Dewey, J. (1971). Experiência e educação. (20a ed.; A. Teixeira, Trad.). Editora Nacional.

Freire, P. (1981). Ação Cultural para a liberdade. (5a ed.). Paz e Terra.

Freire, P. (2016). Pedagogia da autonomia: saberes necessários à prática educativa. (54a ed.). Paz e Terra.

Freire, P. (2011). Pedagogia do oprimido. (50a ed.). Paz e Terra.

Galiazzi, M. do C, et al. (2013). Cirandar: rumo a comunidades aprendentes na formação acadêmico-profissional em roda. In: M. do C. Galiazzi (Org). Cirandar: rodas de investigação desde a escola. (155-168). Oikos. 
Research, Society and Development, v. 10, n. 5, e19410514863, 2021

(CC BY 4.0) | ISSN 2525-3409 | DOI: http://dx.doi.org/10.33448/rsd-v10i5.14863

Galiazzi, M. do C., \& Schmidt, E. B. (2016). Cirandar 2014: rodas de investigação desde a escola. In: M. do C. Galiazzi (Org). Cirandar: rodas de investigação desde a escola. (13-19). Ed. da FURG.

Honneth, A. (2003). Luta por reconhecimento: a gramática real dos conflitos sociais. (L. Repa Trad.). Editora 34.

Larrosa, J. (2015). Tremores: escritos sobre experiência. (C. Antunes, J. W. Geraldi Trad.). Autêntica Editora.

Lidoino, A. C. P., Santos, D. M. dos, \& Reis, G. de A. (2020). Reflexões sobre a formação continuada de professores na contemporaneidade. Research, Society and Development, 9(9), e19996473. https://doi.org/10.33448/rsd-v9i9.6473

Moraes, R. \& Galiazzi, M. do C. (2011). Análise Textual Discursiva. (2a ed.). Unijuí.

Menezes, C. C. de O., Lobato, D. M. N. \& Silva, V. L. R. S. (2021). A Formação Continuada e suas Implicações na prática pedagógica de professores: uma reflexão possível. Research, Society and Development, 10(3), e24210313224. https://doi.org/10.33448/rsd-v10i3.13224

Oliveira, L. R. de. (2019). A (re)significação da docência no Projeto Cirandar. .

Pimenta, S. G. \& Lima, M. S. L (Org). (2010). Estágio e Docência. (5a ed.). Cortez.

Reis, M. A., Nantes, E. A. S., \& Maciel, C. M. L. A. (2019). Uma investigação do processo de formação continuada ofertado pelo Centro de Formação e Atualização dos Profissionais de Cuiabá-MT. Research, Society and Development, 8(6), e786948. https://doi.org/10.33448/rsd-v8i6.948

Santos, L. L.; Montiel, F. C. \& Afonso, M. R. (2021). Processos de formação continuada: alinhando práticas e construindo saberes na Educação Física escolar. Motrivivência, 33(64), 01-24. https://doi.org/10.5007/2175-8042.2021e77032

Schmidt, E. B. \& Galiazzi, M. do C. (2013). A integração universidade-escola básica no Projeto Cirandar. In: M. do C. Galiazzi (Org). Cirandar: rodas de investigação desde a escola. (11-24). Oikos.

Schön, D. A. (2000). Educando o Profissional Reflexivo: um novo design para o ensino e a aprendizagem. (R. C. Costa Trad.). Artmed.

Tardif, M. (2004). Saberes docentes e formação profissional. (4a ed.). Vozes.

Silva, P. da R. L., Santos, L. L., Montiel, F. C., \& Pinheiro, E. dos S. (2021). Projeto Rede de Parceiros Multiplicadores de Esporte Educacional: impacto na prática pedagógica. Research, Society and Development, 10(2), e28210212560. https://doi.org/10.33448/rsd-v10i2.12560

Trevisan, A. (2014). Reconhecimento do outro: teorias filosóficas e formação docente. Mercado de Letras.

Vasconcellos, C. dos S. (2015). Planejamento: projeto de ensino-aprendizagem e Projeto Político Pedagógico - elementos metodológicos para elaboração e realização. (25a ed.). Libertad Editora.

Wenger, E. (1998). Communities of practice. Cambridge Press. 